University of Southern Denmark • Syddansk Universitet

\title{
Exploring the relationship between costs and quality \\ - Does the joint evaluation of costs and quality alter the ranking of Danish hospital departments?
}

Anne Hvenegaard, Danish Institute for Health Services Research DK- Copenhagen and Institute for Public Health - Health Economic Unit, University of Southern Denmark, Odense,

Jacob Nielsen Arendt, Institute for Public Health - Health Economic Unit, University of Southern Denmark

Andrew Street, Centre for Health Economics, University of York, England

Dorte Gyrd-Hansen, Danish Institute for Health Services Research and Institute for Public Health Health Economic Unit, University of Southern Denmark

Corresponding Author: Anne Hvenegaard, ah@dsi.dk, Tel: +45 3529 8422, Fax: +45 35298499

Health Economics Papers

2009:6

UNIVERSITY OF ISOUTHERN DENMARK 
Exploring the relationship between costs and quality in Danish hospital department

\section{Contents}

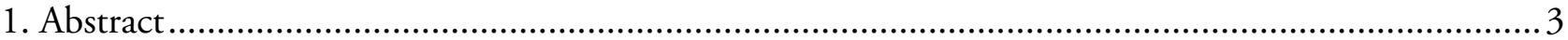

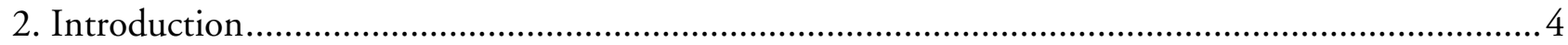

2.1 Theoretical framework for analysing the cost quality relationship...................................... 5

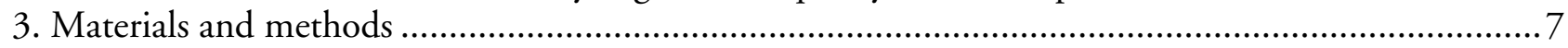

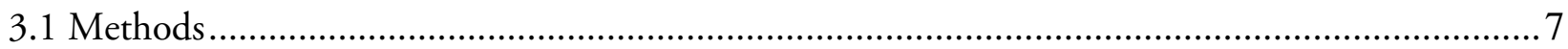

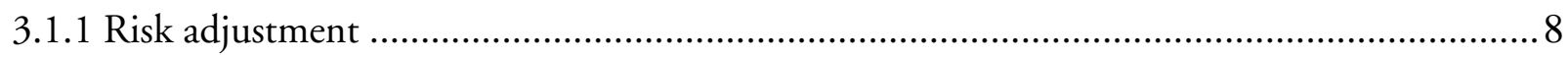

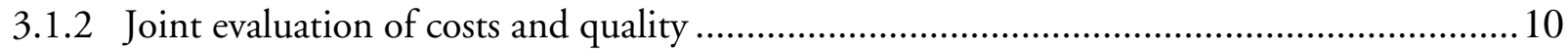

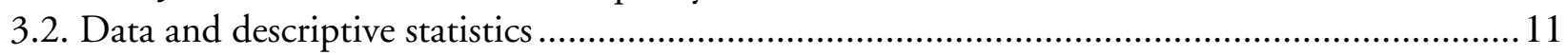

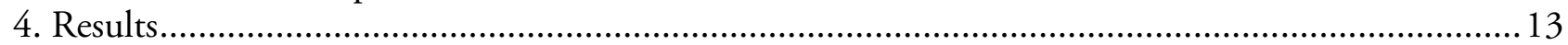

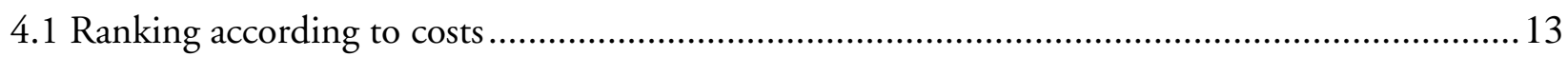

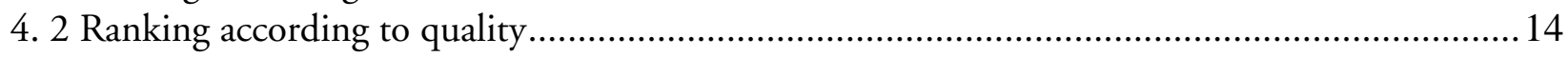

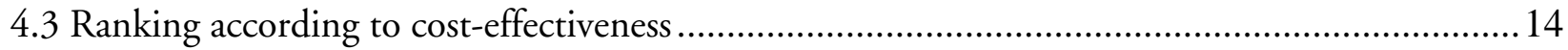

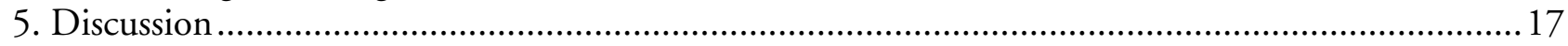

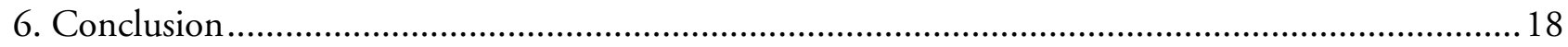

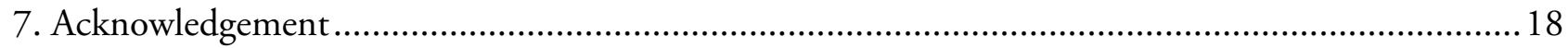

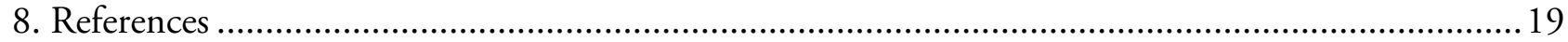




\section{Abstract}

\section{Objective:}

The purpose is to assess whether the joint evaluation of costs and quality affects the ranking of hospital departments relative to performance based on cost performance alone.

\section{Methods:}

Using patient level data, in which 3,754 patients across six vascular departments are pooled we estimate fixed effect models for costs (linear) and quality (logistic). We consider two quality measures; mortality and wound complications. To assess whether the joint evaluation of costs and quality affects the ranking of departments, we construct joint confidence regions for each pair of departmental effects for costs and quality by using a bootstrap method and rank departments according to their costeffectiveness ratio.

\section{Results:}

The association between cost and quality differs depending on how which quality is measured. Lower costs tend to associate with higher mortality, implying a cost-quality trade-off. In contrast there is no clear association between costs and wound complications among vascular departments.

\section{Conclusions:}

Compared to benchmarking of departments based solely on their costs, we show that the ranking of departments may be altered considerably when quality is taken into account. Consequently, it is important to have a well-rounded view of departmental objectives when undertaking performance evaluation.

\section{Keywords:}

Hospital costs, efficiency, quality, cost-effectiveness 


\section{Introduction}

In the past decade there has been a growing interest in many countries in the benchmarking of hospitals measured on the basis of their relative costs. The majority of these efficiency studies do not take quality into account when measuring efficiency or productivity [14].

Broadly speaking, hospital costs are driven by the complexity of the patients treated, as well as efforts to ensure cost control. The complexity of patients can be measured, at least in principle, whereas efforts to ensure cost control are unobservable. In efficiency studies the residual cost after taking into account the types of patients treated is interpreted as insufficient effort to control costs (often labelled 'inefficiency'). But this labelling might be inaccurate because the residual cost may be capturing other unmeasured aspects of the care process. Most particularly, if hospitals choose to provide a higher level of quality this may be reflected in the residual costs and thus misinterpreted as inefficiency. The concern is that if quality is not considered or taken into account hospitals may respond by reducing the level of quality provided. Whether this happens is a matter of controversy and depends on whether or how costs and quality are related.

More solid empirical evidence on how costs and quality are related is needed in order to achieve a better understanding of the possible implications of moving from relative efficiency as a benchmark indicator to also including quality in the objective function. Clearly, if there is a cost quality trade-off, and if we consider quality as a relevant output, we need to take quality differences into account in order to provide incentives for hospitals to produce higher levels of quality. How this should be done is not obvious. Some studies have included quality measures as additional control variables in efficiency analysis, see for example Carey and Burgess (1999) and McKay and Deily [2, 18]. These studies are subject to the problem of potential endogeneity of quality with respect to costs, which is inherently difficult to solve. Other alternatives are discussed in Hauck \& Street (2006) in the more general case of having multiple objectives (among which efficiency and quality are two) [13]. They discuss three alternatives; analyses of the objectives in isolation, calculation of an index in which the different objectives are weighted somehow, and the use of multivariate models accounting for correlation among objectives.

This study seeks to provide new evidence on the cost-quality relationship in hospital departments. We provide a theoretical framework for discussing the relationship between costs and quality that also underpins the identification problem. We propose a separate analysis of costs and quality, thereby avoiding the causal identification problem. We account for potential correlation between costs and quality when conducting inference on their relationship (using a bootstrap procedure). Also, we address the issue of multiple criteria by using cost-effectiveness as a ranking device.

A number of remarks on previous related studies are in place. Previous studies have suggested that specialty-level analysis is preferable to hospital-level analysis [12, 23]. The advantage when analysing departments instead of hospitals is that it is more likely that there is greater homogeneity in the types of 
patients treated as well as greater standardisation in the production process [12]. Clearly, the drawback is that there is a smaller number of comparators, such as in the present study where we operate with six vascular departments only. This is an inherent drawback in many contexts, such as smaller countries where a larger sample size simply cannot be realised. To overcome this, an earlier study has demonstrated that inferences among a small number of organisations can be improved by exploiting patient-level data [23]. In the present study we have access to the same patient-level cost data as in Olsen \& Street (2008) [23]. They demonstrated that it was possible to identify those departments that were statistically significantly more technically efficient than others. In the present study we extend this analysis by exploring what effect the incorporation of quality has on the efficiency of the various departments.

The paper is organised as follows. First, we discuss what quality measures to apply in efficiency analyses and provide an analytical framework for analysing the association between costs and quality. Second, we outline our methodological approach. Third, we describe the data available and provide some descriptives. Fourth, we estimate the departmental efforts in controlling costs and promoting good quality and rank the departments according to these effects separately for costs and quality. Fifth, we explore the relationship between costs and quality for the various departments and explore whether a joint evaluation of costs and quality alters the ranking of departments when compared to rankings based on costs or quality performance alone.

\subsection{Theoretical framework for analysing the cost quality relationship}

Analysing the relationship between costs and quality based on empirical data is challenging and rather different suggestions emerge from the literature as to how costs and quality are related. A clarification of the potential relationships is called for so that studies can be evaluated. In figure 1, three different relationships between costs and quality are presented [7, 20,30].

The downward sloping dotted curve reflects a potential negative association between poor quality and costs. For instance, consider the relationship between adverse events (as a measure of quality) and costs. There seems to be evidence that a higher incidence of adverse events is associated with higher costs. For instance, patients suffering an adverse event tend to be hospitalised for longer. Classen et al (1997) found that the length of stay and costs of hospitalisation for adverse drug events are substantial and also increased the risk of dying [3]. Pinilla et al (2006) found that medical errors for hospitalised patients doubled the cost per patient [24]. Plowman et al (2001) found that patients suffering wound infections are more costly to care for [25]. Surgical complications may also increase length of stay and hospital costs [5]. 
Figure 1: The theoretical relationship between costs and quality

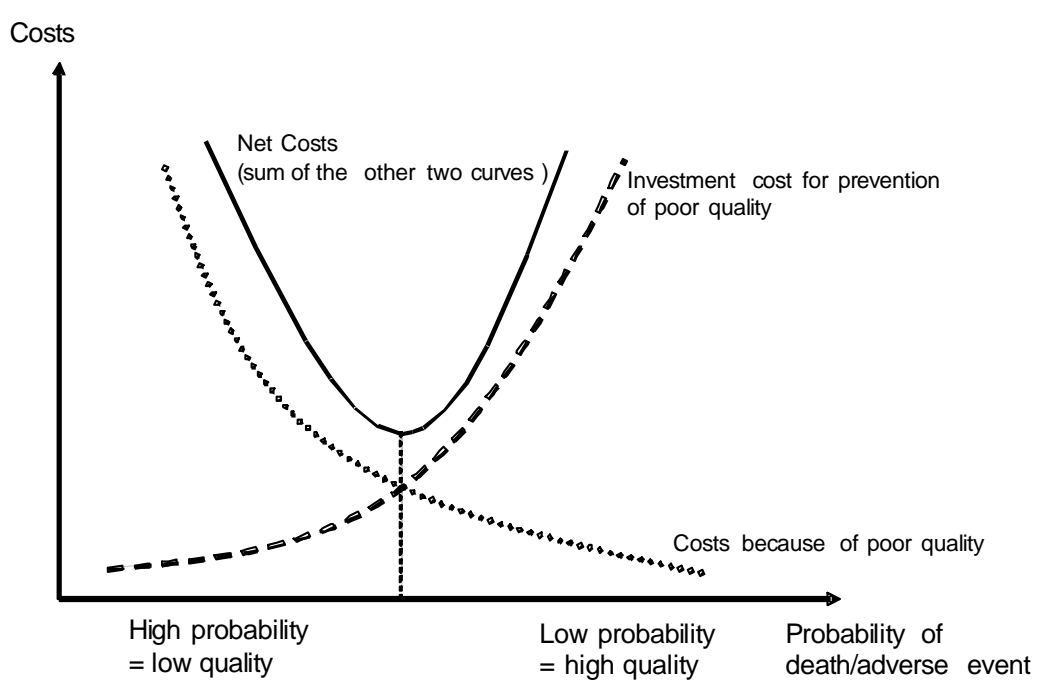

The upward sloping dashed curve reflects a potential positive relationship between investments in quality and the quality level, the expectation being that (costly) investments yield higher levels of quality. A typical example from the literature illustrating this is the association between nurse-topatient-ratios where there is evidence that more nurses per patient is positively related to quality in terms of preventing adverse events [16]. Similarly a higher level of cleanliness may help prevent infections such as Methicillin-Resistant Staphylococcus Aureus (MRSA) [28].

The U-shaped curve represents the net costs associated with different levels of quality. The net cost is the sum of costs associated with adverse events (as illustrated by the downward sloping curve) and costs invested in quality (as illustrated by the upward sloping curve). Cost of treatment is minimised when the slope of the U-shaped curve is zero. Overall quality is maximised when the preventive efforts are as high as possible. Clearly, if there is a choice between minimising costs and maximising quality, there is a cost-quality trade-off. This trade-off is not evident at all levels of cost and quality. At lower levels of quality, investments aimed at improving quality may lower the net costs of treatment.

If indeed the overall relationship between costs and quality takes the form of the $U$ shaped curve it is not surprising that there is a lack of empirical consensus about whether the relationship between costs and quality is negative. The empirical results depend on where hospitals lie along the $U$ shaped curve, and their position will vary from study to study and, perhaps, according to how quality is measured. Some studies have found a positive association between costs and quality suggesting a cost quality tradeoff as illustrated by the upward sloping part of the U-shaped curve in figure 1. Others have found a negative association suggesting that there may be some degree of complementarity and that cost containment and health improvement are compatible goals. Dismuke and Sena (2001) [6] and Sola and Prior (2001) [32] found that it is possible to improve efficiency while at the same time reducing in- 
hospital mortality [6] or percentage of nosocomial infections [27]. Nayar and Ozcan (2008) found that efficient hospitals were also efficient in producing quality [22]. Likewise, a study by Laine et al (2005) found that low quality may be associated with inefficiency [15]. A study by Carey and Burgess (1999) measured quality in terms of mortality and found a positive association between costs and quality because patients who die are more costly to care for [2]. Maniadakis et al (1999) found that when incorporating quality the magnitude of the productivity changes diminish suggesting that to some extent gains in productivity may be at the expense of gains in the level of quality [17]. Morey et al (1992) found that a 1 percent decrease in the ratio of observed to predicted deaths was associated with a 1.34 percent increase in efficient cost [21]. Clement et al (2008) found that poorer patient outcomes in terms of mortality were associated with lower efficiency [4]. Other studies have found the cost quality relationship to be more complex as it changes over the range of quality and depends on the outcome measure employed or how quality is incorporated [8, 9, 19, 26, 35].

Some have argued that higher quality will cost more and that with limited budgets, hospital departments might try to contain costs or reduce unit costs by cutting the resources needed for various services, which is likely to result in poorer quality of care and outcomes. A contrasting argument is that inefficient use of resources may reflect poor management, which is also likely to be associated with poor quality of care. Thus, some hospitals or hospital departments may be operating on the downward sloping part of the U-shaped curve where further investments in preventing poor quality may reduce costs as well as improve quality. This is the case if the hospitals manage to eliminate wasteful costs such as those incurred by poor quality. Others may be operating on the upward sloping part where further investments may improve quality, thus reflecting a cost quality trade-off. Our hypothesis is that the association between net costs and quality may differ among departments. This is what we seek to explore in the present study in order to examine what effect inclusion of quality in the performance criteria may have on the relative performance of hospital departments.

\section{Materials and methods}

\subsection{Methods}

We seek to investigate whether including quality by jointly evaluating costs and quality alters the ranking of hospitals departments based on separate analysis of costs or quality. In these rankings, departmental performance is assessed after controlling for differences in the types of patients treated as a form of risk adjustment. This section describes how the risk adjustment is performed, how costs and quality are separately and jointly analysed, and how rankings are constructed. 


\subsubsection{Risk adjustment}

Following earlier literature $[23,34]$ we conduct the risk adjustment by specifying a fixed effects model to analyse costs of individual patients, recognising the department in which they are treated. We are aiming to include non-controllable factors, i.e. to control for factors outside managerial influence from a departmental perspective. Our model is defined as:

$$
c_{i j}-\alpha+\alpha_{j}+\beta X_{i j}+v_{i j} \quad \quad \sum_{j} \alpha_{j}=0
$$

Where $c_{i j}$ is the cost of patient $i$ in department $j$. $X_{i j}$ is a vector with risk adjustment factors to be specified below. The model has a department specific constant (a fixed effect), $\alpha_{j}$, containing unobserved average characteristics of patients and characteristics of the department in which the patient was treated, and which, without loss of generalization is normalized to sum to zero. The error term $v_{i j}$ captures unobserved characteristics of individual patients [26]. It is the department specific constant that we interpret as the risk adjusted costs and we refer to it as the "departmental effect". When the number of departments is small the departmental effect can be estimated by the LSDV estimator obtained as OLS estimates of (1) with dummies for each department included as regressors. Given the LSDV estimates of $\alpha$ and $\beta$, one can write the LSDV estimates of $\alpha_{j}$ as:

$$
\hat{\alpha}_{j}=\bar{c}_{j}-\hat{\alpha}-\hat{\beta} \bar{X}_{j}
$$

This is an unbiased estimate of the true but unknown department effect provided that risk adjustment factors are strongly exogenous (e.g. Wooldridge, 2002 [36]):

$$
E\left(v_{i j} \mid X_{1 j}, \ldots, X_{n_{j} j}\right)=0
$$

Given the exogeneity assumption we can also formally define department effects more generally as the difference between observed department costs and expected department costs, where expectation is formed using only risk adjustment factors but no department information:

$$
\alpha_{j}=\bar{c}_{j}-E\left(\bar{c}_{j} \mid \alpha, \beta, \bar{X}_{j}\right)
$$

Where top bars denote empirical means, here across patients within department $j$. The department effect is positive if departments have higher costs than expected and negative if departments are costsaving compared to the expected. Note that using a fixed effect specification has two clear advantages compared to a random effects estimator: 1) It provides explicit estimates of the department effects for the given departments of interest and 2) It is unbiased even if risk adjustment factors, $X$, and the departmental effects $\alpha_{j}$ are correlated. Such a correlation may arise if departments are acting upon knowledge of risk adjustment factors, which in our view seems realistic. Moreover, the fixed effects correspond to stochastic frontier analysis (SFA) estimates of inefficiency (after subtracting the minimum fixed effect), see for example Wagstaff (1989) and Schmidt \& Sickles (1984) [29, 34]. Compared to cross-sectional estimates no distributional assumptions are needed and compared to traditional panel estimates our multilevel estimates do not suffer from the assumption that inefficiency is time-invariant. 
The interpretation and properties of the fixed effect estimates hinges crucially, however, on what is in the conditioning set $X$, the risk adjustment factors. The risk adjustment factors should, we believe, be factors that influence costs and quality, but which are beyond the control of the department. There is no clear-cut agreement on which variables qualify as 'acceptable' risk adjustment factors. This resembles the problems of adjustments made in the social choice literature on fair compensation, needs adjustment in inequity measurement, and risk adjustment in the insurance literature, see for example Gravelle (2003) or Schokkaert \& Van de Voorde (2004) [10, 31]. Here, we define risk adjustment factors to be mainly pre-hospitalization patient characteristics listed in table 1 . Factors within the control (in principle at least) of the departments such as length of stay, use of specific procedures, the amount of staff per patient etc. are considered to be endogenous and therefore not applied as controls in the models. As such, (1) can be viewed as a reduced form equation. Having specified the risk adjustment factors, it should be noted that while the departmental effect in part reflects the various departments' ability in controlling costs for their patients after taking into account the types of patients treated, they also absorb any unobserved differences in patient characteristics that may vary systematically between departments. Note that provider characteristics cannot be included as risk adjustment factors because they are absorbed by the fixed effect. The departmental effects, therefore, also reflect differences in provider characteristics. Some of these might be exogenous, at least in the short run, such as whether the department is specialised or non-specialised.

Risk adjustment for quality outcomes follows the same line of overall reasoning as for costs. We could specify a linear fixed effect model just as for costs, but given that the quality measures we consider are binomial and therefore the mean outcome non-linearly related to risk adjustment factors by construction, this would provide biased risk adjustments. We therefore specify a logistic regression model for quality outcomes:

$$
q_{i j}=1\left(\gamma_{j}+\delta X_{i j}+\varepsilon_{i j}>0\right), \sum_{j} \gamma_{j}=0
$$

where $q_{i j}$ is the quality outcome for patient $i$ in department $j$ and 1() is the indicator function. $X$ is the same vector of risk adjustment factors as for costs, see table $1 . \gamma_{j}$ is a department specific constant, and the error term $\varepsilon_{i j}$ captures the unexplained variation in patient quality. We assume that the errors are logistically distributed, so that the model becomes a logit model:

$$
\operatorname{Pr}\left(q_{i j}=1 \mid X_{i j}\right)=\operatorname{Pr}\left(\gamma_{j}+\delta X_{i j}+\varepsilon_{i j}>0\right)=\operatorname{Pr}\left(\varepsilon_{i j}<\gamma_{j}+\delta X_{i j}\right) \quad=\quad \frac{e^{\gamma_{j}+\delta X_{i j}}}{1+e^{\gamma_{j}+\delta X_{i j}}}
$$

The $\gamma_{j}$ are departmental quality effects in the same sense as $\alpha_{j}$ are departmental cost effects in the cost equations. Note that they are measured on a logistic scale, so for ease of interpretation we instead define the departmental quality effect as the difference between observed and expected quality, where expectation is taken with respect to observed patient characteristics. This also provides a risk adjustment that follows the more general definition provided in (4). As the overall mean predicted quality does not correspond to overall mean observed quality in logistic models, we adjust the effect to ensure that the departmental quality effect is still measured relatively to an overall zero mean. If $q$ is an indicator of 
good quality, we define our departmental quality effect as (and with opposite sign if $q$ is an indicator of poor quality):

$$
\begin{array}{r}
\hat{\mu}_{j}=\bar{q}_{j}-\hat{E}\left(\bar{q}_{j} \mid X_{i j}\right)-\left[\bar{q}-\hat{E}\left(\bar{q} \mid X_{i j}\right)\right] \\
\hat{E}\left(\bar{q}_{j} \mid \delta, X_{i j}\right)=\sum_{i=1}^{n_{j}} \frac{e^{\widehat{\delta} X_{i j}}}{1+e^{\widehat{\delta} X_{i j}}}
\end{array}
$$

The last terms in the bracketed parenthesis is the adjustment to ensure an overall zero mean. Note that it is just a constant subtracted from all department estimates.

\subsubsection{Joint evaluation of costs and quality}

In order to rank the departments on the basis of information on quality and costs, we calculate a cost quality ratio similar to what is done in a cost-effectiveness analysis. This involves dividing the departmental effect for costs with the departmental effect for the quality measure for each department. This exercise is equivalent to ranking the departments according to their average cost per unit of quality. If a department provides above average quality, a high degree of cost-effectiveness requires that the added quality is obtained at the lowest possible excess costs. In contrast, for those departments providing below average quality it would require that they compensate by higher cost savings in order to obtain the same cost quality ratio as a department with above average quality. In this way, the two departments may obtain the same cost quality ratio and be equally cost effective.

By plotting the departmental effects into a diagram according to the department's cost performance (on the $y$-axis) and quality performance (on the x-axis) we get something that is analogous to a costeffectiveness plane, since it provides us with four quadrants. We are able to place each department in one of four quadrants (figure 2 and 3). First, we have the north-eastern quadrant where quality is above average and where the quality is obtained at higher than average costs. Second, we have the southwestern quadrant where departments provide lower than average quality but at lower than average cost. Third, there is the south-eastern quadrant where departments provide lower quality at lower than average cost. Fourth, the north-western quadrant where departments provide above average quality at higher than average cost.

To assess whether the joint evaluation of costs and quality affects the ranking between departments significantly, we construct joint confidence regions for each pair of departmental effects for costs and quality. We use a likelihood based method to construct the confidence region, where the joint likelihood of costs and quality are estimated by a non-parametric kernel density on bootstrap samples of cost and quality departmental effects [11] $]^{1}$. We use non-parametric bootstrapping with replacement within department strata and we use 10,000 bootstrap samples. Quality and cost samples are parallel

\footnotetext{
${ }^{1}$ We use a Gaussian kernel and experiment with different bandwidths. The plots shown in section 5 have bandwidths of one standard deviation for costs and quality. Similar results are obtained with half or twice the size of these bandwidths.
} 
selected implying that a potential covariance between costs and the quality measure is taken into account, without assuming joint normality of costs and quality. When comparing costs and quality among hospital departments we rely on the confidence intervals and a 5\% significance level.

\subsection{Data and descriptive statistics}

Data were available for all patients admitted for vascular surgery (3,754 patients) in six (out of eight $)^{2}$ vascular departments in Denmark in 2004.

Data on wound complications and patient characteristics are drawn from The Danish Vascular Registry, which is a national (clinical) registry for quality measures and detailed patient characteristics for all vascular hospital departments in Denmark [33]. The Danish Vascular Registry was established by the Danish Vascular Society and contains information on patient specific characteristics such as age, gender, smoking status, disease status (including previous diseases) and surgical information. The main purpose of the Danish Vascular Registry is to monitor quality of care. Data on 30 day mortality are drawn from The Causes of Death Registry.

The cost data were taken from the National Cost database and cover the resources used during admission for intensive care, laboratory tests, procedures, ward stays etc. The National Cost Database is based on patient-level data reported by each hospital according to accounting guidelines set out by the National Board of Health and, for ancillary services, by applying a national set of relative service weights. The National Cost Database is the basis of the Danish case-mix system DkDRG, under which hospitals are reimbursed [1].

Table 1 describes the variables applied in the analysis and provides basic descriptive statistics for the sample as a whole.

\footnotetext{
${ }^{2}$ The remaining two departments were excluded because they did not provide complete cost data.
} 
Table 1: Descriptive statistics: Hospital characteristics, costs, quality and patient characteristics

\begin{tabular}{|c|c|c|c|c|c|c|c|c|}
\hline & Description & Mean \% & $A$ & $B$ & $C$ & $D$ & $E$ & $F$ \\
\hline $\begin{array}{l}\text { Specialised/non- } \\
\text { specialised }\end{array}$ & - & & Non & Non & Spec. & Non & Spec. & Spec. \\
\hline Location & - & & City & City & $\begin{array}{l}\text { Capital } \\
\text { area }\end{array}$ & City & City & Capital \\
\hline $\mathrm{N}$ & - & & 430 & 701 & 771 & 400 & 527 & 899 \\
\hline $\begin{array}{l}\text { Costs } \\
\text { (observed) }\end{array}$ & Average observed cost, DKK & & 44,648 & 56,095 & 59,634 & 63,070 & 69,524 & 66,782 \\
\hline \multicolumn{9}{|l|}{$\begin{array}{l}\text { Quality } \\
\text { variables: }\end{array}$} \\
\hline 30 day mortality & $\begin{array}{l}\begin{array}{l}\text { Death within } 30 \\
\text { admission }\end{array} \\
\end{array}$ & 5.29 & 2.60 & 7.28 & 6.31 & 2.12 & 4.10 & 6.28 \\
\hline $\begin{array}{l}\text { Wound } \\
\text { complications }\end{array}$ & $\begin{array}{l}\text { Dummy of } 1 \text { if the patient has } \\
\text { suffered a wound complication. } \\
\text { Includes all wound complications } \\
\text { (hematoma, lymph oozing }>2 \text { days } \\
\text { \& edge necrosis) }\end{array}$ & 11.17 & 20.4 & 8.28 & 7.12 & 11.85 & 8.08 & 13.67 \\
\hline \multicolumn{9}{|l|}{$\begin{array}{l}\text { Patient } \\
\text { characteristics }\end{array}$} \\
\hline Case mix index & $\begin{array}{l}\text { DRG-weight for the individual } \\
\text { patient divided by the average } \\
\text { DRG-weight for all patients } \\
\text { (continuous variable) }\end{array}$ & 1.00 & 0.89 & 1.16 & 1.05 & 0.99 & 1.07 & 0.85 \\
\hline Age, years & Continuous variable & 65.96 & 67.89 & 67.35 & 66.23 & 65.88 & 65.98 & 63.84 \\
\hline $\mathrm{Age}^{2}$, years & Continuous variable & 4,530 & 4,724 & 4,694 & 4,602 & 4,458 & 4,510 & 4,304 \\
\hline Male & Dummy of 1 if the patient is male & 57.88 & 0.55 & 0.59 & 0.54 & 0.56 & 0.66 & 0.58 \\
\hline $\begin{array}{l}\text { Smoker/ex- } \\
\text { smoker }\end{array}$ & $\begin{array}{l}\text { Dummy of } 1 \text { if the patient is } \\
\text { smoker or ex-smoker }\end{array}$ & 72.27 & 0.71 & 0.69 & 0.72 & 0.83 & 0.75 & 0.69 \\
\hline Emergency & $\begin{array}{l}\text { Dummy of } 1 \text { if the patient is acute } \\
\text { (emergency) }\end{array}$ & 34.96 & 0.26 & 0.36 & 0.36 & 0.26 & 0.32 & 0.43 \\
\hline Home care & $\begin{array}{l}\text { Dummy of } 1 \text { if the patient } \\
\text { requires home care }\end{array}$ & 19.30 & 16.27 & 26.82 & 12.89 & 16.71 & 19.79 & 20.95 \\
\hline Cerebrovascular & $\begin{array}{l}\text { Dummy of } 1 \text { if the patient has } \\
\text { been treated for TIA/amaurosis } \\
\text { or stroke }\end{array}$ & 14.60 & 18.65 & 8.53 & 15.34 & 9.42 & 20.33 & 15.68 \\
\hline Hypertension & $\begin{array}{l}\text { Dummy of } 1 \text { if the patient has } \\
\text { hypertension }\end{array}$ & 47.10 & 48.85 & 57.14 & 43.69 & 49.28 & 45.66 & 41.36 \\
\hline Cardial & $\begin{array}{l}\text { Dummy of } 1 \text { if the patient has } \\
\text { been treated for cardiac disease }\end{array}$ & 30.31 & 31.17 & 33.98 & 33.25 & 24.04 & 27.99 & 28.81 \\
\hline Pulmonal & $\begin{array}{l}\text { Dummy of } 1 \text { if the patient has } \\
\text { been treated for pulmonary } \\
\text { disease }\end{array}$ & 13.11 & 13.17 & 14.23 & 16.37 & 9.05 & 12.09 & 11.96 \\
\hline Diabetes & $\begin{array}{l}\text { Dummy of } 1 \text { if patient has type } 1 \\
\text { or } 2 \text { diabetes }\end{array}$ & 16.08 & 15.37 & 16.85 & 18.04 & 17.10 & 13.05 & 15.50 \\
\hline ASA score & $\begin{array}{l}\text { Categoric variable (1-5) of the } \\
\text { severity of the patient's condition. } \\
1 \text { is normal health condition and } 5 \\
\text { is expected death within } 24 \text { hours } \\
\text { without treatment. }\end{array}$ & 2.09 & 2.09 & 2.24 & 1.97 & 2.00 & 1.82 & 2.27 \\
\hline $\begin{array}{l}\text { Intensive care }> \\
3 \text { days }\end{array}$ & $\begin{array}{l}\text { Dummy of } 1 \text { of the patient is } \\
\text { treated in intensive care for more } \\
\text { than } 3 \text { days }\end{array}$ & 0.70 & 0.65 & 0.81 & 0.13 & 0.23 & 2.14 & 0.51 \\
\hline
\end{tabular}




\section{Results}

\subsection{Ranking according to costs}

In table 2 the results from a fixed effect cost model (equation 1) are presented. The departmental effects can be interpreted as departmental performance in exerting cost control after taking into account the types of patients treated. The estimates reflect the deviation from the overall expected mean. A departmental effect below zero means that the department has lower costs than expected given the types of patients treated and vice versa for a departmental effect above zero.

The departments can be sorted into three groups. Three departments (B, A and C) have negative departmental effects (lower costs than expected given the patients they treat), one department has an average departmental effect (D) (with confidence intervals crossing zero) and two departments exhibit positive departmental effects (E and F).

Table 2: Deviation in costs from overall expected mean (departmental effects), DKK ${ }^{\mathrm{i}}$ [95\% CI] (* if significant at 5\%)

\begin{tabular}{|l|r|}
\hline Department & Departmental effect ${ }^{\text {ii) }}$, DKK \\
\hline B & $-11,549^{*}$ \\
\hline A & {$[-14,610 ;-8,596]$} \\
\hline C & $-11,355^{*}$ \\
& {$[-14,733 ;-7,953]$} \\
\hline D & $-3,026^{*}$ \\
& {$[-6,049 ;-9.2]$} \\
\hline E & 1,707 \\
& {$[-1,602 ; 4,961]$} \\
\hline F & $7,002^{*}$ \\
& {$[3,289 ; 11,149]$} \\
\hline $\begin{array}{l}\text { i) The weighted sum of departmental effects is zero. The departmental effects are calculated as regression } \\
\text { post estimation in intercooled stata } 9.2\end{array}$ \\
ii) The results for the covariates (listed in table 1) have the expected sign. The full set of results is not shown but can be obtained \\
upon request to the authors
\end{tabular}




\section{2 Ranking according to quality}

In table 3 the results from the fixed effect quality model (equation 2) are presented for the two quality measures applied along with $95 \%$ confidence intervals. The departments are ranked according to their departmental effect with the first listed performing best for the specific quality measure. The departmental effects can be interpreted as deviation in risk of dying or suffering wound complications from overall expected mean. A departmental effect above zero can be interpreted as indicative of good departmental performance since the department has a higher level of quality than expected given the patients it treats.

The departments perform quite differently according to the quality measure applied. For example department A ranks highest according to mortality and lowest according to wound complications. Department B ranks lowest according to mortality and second highest according to wound complications.

Table 3: Overall expected risk minus departmental risk per patient (i.e. departmental effects), percentage points) $[95 \% \mathrm{CI}]\left({ }^{*}\right.$ if significant at $\left.5 \%\right)$.

\begin{tabular}{|l|l|l|l|}
\hline \multicolumn{2}{|c|}{30 day mortality \% } & \multicolumn{2}{c|}{ Wound complication \% } \\
\hline Department & Departmental effect & Department & Departmental effect \\
\hline A & $\begin{array}{l}0.0185 \\
{[-0.0005 ; 0.0344]}\end{array}$ & C & $\begin{array}{l}0.0469 * \\
{[0.0283 ; 0.0657]}\end{array}$ \\
\hline D & $\begin{array}{l}0.0163 * \\
{[0.016 ; 0.0298]}\end{array}$ & B & $\begin{array}{l}0.0435 * \\
{[0.0223 ; 0.0639]}\end{array}$ \\
\hline E & 0.0057 & E & $\begin{array}{l}0.0219 \\
{[-0.0031 ; 0.0448]}\end{array}$ \\
\hline F & {$[-0.0088 ; 0.0198]$} & & -0.0097 \\
& 0.0036 & D & {$[-0.0406 ; 0.0205]$} \\
\hline C & {$[-0.0082 ; 0.0155]$} & & $-0.0362 *$ \\
& -0.0121 & F & {$[-0.0561 ;-0.0165]$} \\
\hline B & {$[-0.0264 ; 0.0019]$} & & $-0.0983 *$ \\
& $-0.0162 *$ & A & \\
\hline
\end{tabular}

\subsection{Ranking according to cost-effectiveness}

We illustrate the relationship between departmental costs and mortality (figure 2) or wound complications (figure 3) respectively. It is apparent that the departments are placed in different quadrants suggesting that they perform quite differently across these dimensions. The confidence regions, as depicted by the ellipses, suggest that statistically significant differences in performance are less prevalent when performance is measured in terms of costs and quality rather than costs alone. 
Figure 2 shows that five out of the six departments are placed in one of the two trade-off quadrants, where lower costs are associated with lower quality (SW quadrant) or higher costs are associated with higher quality (NE quadrant). Overall, then, one may cautiously suggest that there appears to be a cost quality trade-off for costs and mortality. Figure 3, however, shows that this conclusion is sensitive to the quality measure. When quality is measured by wound complications rather than mortality, departments appear in all four quadrants.

Figure 2: Difference between observed and expected cost (DKK) per patient, and difference between expected and observed mortality within 30 days per patient and $95 \%$ confidence regions, by department ${ }^{3}$

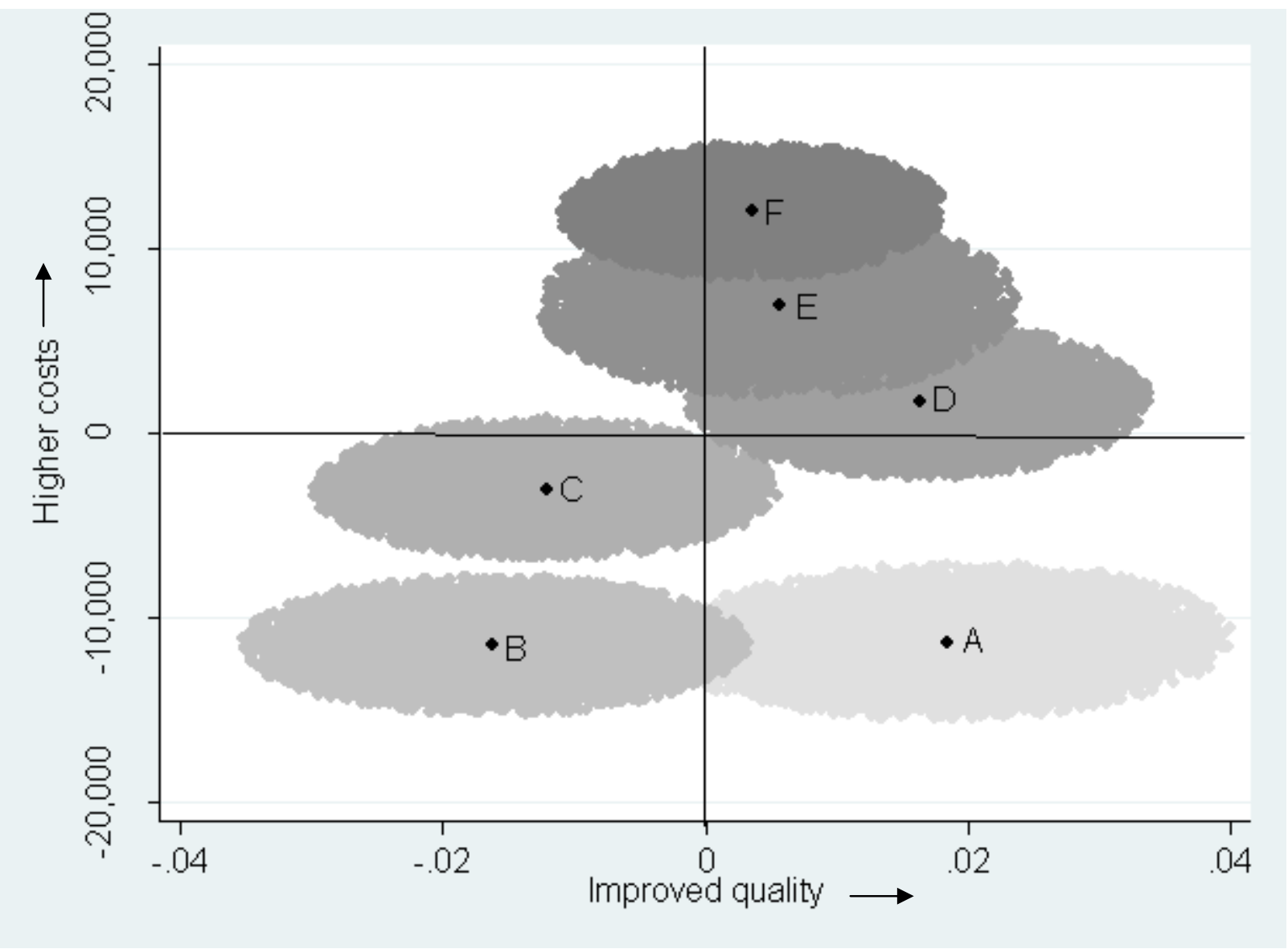

\footnotetext{
${ }^{3}$ Differences between observed and expected costs, and expected and observed risk of dying per patient corresponds to the departmental effects for costs and quality respectively.
} 
Figure 3: Difference between observed and expected cost (DKK) per patient, and difference between expected and observed risk of suffering wound complications per patient and $95 \%$ confidence regions, by department

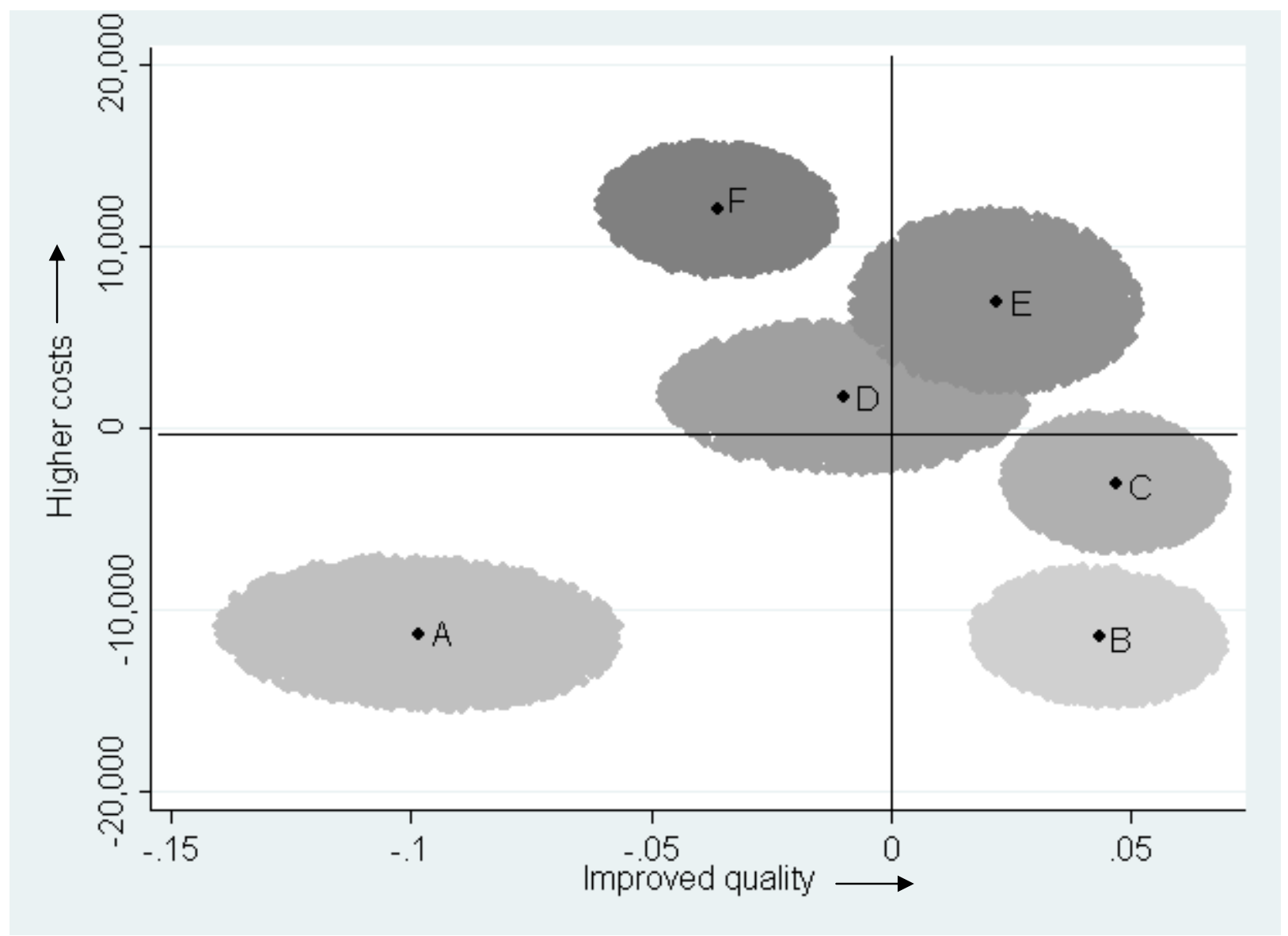

In table 4 we list the ranking of departments when these are benchmarked according to cost, quality and cost-effectiveness, respectively. We interpret the relative cost effectiveness from figures 2 and 3 in the following way; Departments placed in the south-eastern quadrant are ranked as the most costeffective departments (with those departments exhibiting a steeper slope relative to the origin being the most cost effective). Departments placed in the south-western or the north-eastern quadrants follow in relative cost-effectiveness. Finally, those departments which are to be found in the north-western quadrant exhibit the lowest cost effectiveness with those placed more steeply relative to the origin demonstrating the worst cost effectiveness ratio.

From table 4 we see that choice of performance indicator has implications for the ranking of departments. If benchmarking focuses on cost minimisation department B is ranked highest (column 1). But risk-adjusted mortality is highest in this department (column 2). If one also takes into account how this department performs with respect to costs and mortality, department B ranks number three in terms of cost effectiveness (column 3). Similarly, department A moves from being ranked the lowest 
when focus is wound complications (column 4), whereas the department is ranked third when costs and wound complications are analysed jointly (column 5).

Table 4: Ranking of departments according to costs, quality and cost-effectiveness

\begin{tabular}{|c|c|c|c|c|}
\hline & \multicolumn{2}{|c|}{30 day mortality } & \multicolumn{2}{|c|}{ Wound complication } \\
\hline Lower Cost & $\begin{array}{l}\text { Lower } \\
\text { Mortality }\end{array}$ & $\begin{array}{l}\text { Higher } \\
\text { costs effectiveness }\end{array}$ & $\begin{array}{l}\text { Fewer } \\
\text { Wound complications }\end{array}$ & $\begin{array}{l}\text { Higher } \\
\text { Cost effectiveness }\end{array}$ \\
\hline $\mathrm{B}$ & $\mathrm{A}$ & A & $\mathrm{C}$ & B \\
\hline A & $\mathrm{D}$ & $\mathrm{D}$ & B & $\mathrm{C}$ \\
\hline $\mathrm{C}$ & $\mathrm{E}$ & B & $\mathrm{E}$ & $A$ \\
\hline $\mathrm{D}$ & $F$ & $\mathrm{C}$ & $\mathrm{D}$ & $E$ \\
\hline $\mathrm{E}$ & $\mathrm{C}$ & $\mathrm{E}$ & $\mathrm{F}$ & D \\
\hline $\mathrm{F}$ & B & $\mathrm{F}$ & $\mathrm{A}$ & $\mathrm{F}$ \\
\hline
\end{tabular}

\section{Discussion}

We compare rankings of departments with and without consideration of quality aspects. This approach delivers an univariate decision criterion from a pair of objectives without the need to specify relative weights on the objectives or to address their causal relation. We also suggest procedures of inference that take a correlation between costs and quality into account. A potential drawback of the separate estimation of cost and quality is that estimated equations might suffer from omitted variable bias. How to address this without a solid strategy for solving the causal identification problem is not obvious. When departments are ranked according to cost-effectiveness rather than cost minimisation (or quality maximization) it produces a different ordering of departments. There does not appear to be systematic differences in the ordering according to hospital characteristics (listed in table 1) although when considering costs alone, there is a tendency for better performance for non-specialised hospitals and lower performance for specialised hospitals. Due to a large degree of statistical uncertainty surrounding mortality and wound complications (the latter to a lesser extent), the ranking is not consistently based on statistically significant differences in cost effectiveness. It should, however, be acknowledged that ranking according to relative cost-effectiveness implies that the aim is to minimise the cost per unit of quality produced. In the case that higher levels of quality are associated with higher marginal costs (an assumption which is not confirmed by our study) and assuming there is a societal willingness to pay such a higher price, this simple cost effectiveness criteria would be invalid.

We have interpreted the departmental effects as the departments' ability in promoting good quality and cost control for their patients after taking into account the types of patients treated. However, it cannot be ruled out that the departmental effect partly captures unobserved patient characteristics and other factors beyond the control of the department or long-run provider characteristics that should ideally be controlled for. So even though we have controlled for a large number of patient characteristics in our analyses, there may be further explanations outside the managerial influence that we have been unable 
to account for due to lack of data. For instance, there may be differences in environmental circumstances such as in the primary health care sector.

A further limitation of our study is that our results are based on observations of six departments only (due to limited number of vascular departments in Denmark). This means we cannot provide a general cost-quality relationship in terms of statistical significance, but merely in terms of trends. Having few departmental observations is often bound to be an unavoidable constraint that the analyst must accept when seeking to analyse such relationships. This is especially the case in a small country like Denmark where the number of departments within a specialty often includes as few as five to seven departments. We have, however, attempted to take this problem into account by applying a bootstrap method enabling us to consider uncertainty when calculating average departmental effects.

\section{Conclusion}

Our study demonstrates that an implication of taking quality into account when comparing efficiency is that it alters the ranking of the departments. For mortality a cautious conclusion is that there is a cost quality trade-off, implying that taking quality into account may offer some explanation of differences in efficiency. For wound complication, however, there does not appear to be a systematic pattern of association between costs and quality for either low- or high-performing departments. This suggests that, in our study, consideration of quality in terms of wound complication is somewhat inconclusive as to how it affects efficiency. Of course more research into this rather complex interaction between efficiency and quality performance is needed before it is possible to draw general conclusions as to the relationship between costs and quality. We have set out a framework for evaluating this relationship and devised an empirical strategy that can be employed even when the analyst is faced with a small number of hospital departments. Compared to benchmarking of departments based solely on their costs, we have seen that the ranking of departments may be altered considerably when quality is taken into account. This lends further support to having a well-rounded view of departmental objectives when undertaking performance evaluation.

\section{Acknowledgement}

We acknowledge the Danish Vascular Registry and the National Board of Health for provision of data. Thanks to all the participating Vascular Departments and in particular consultant and chairman of the Danish Vascular Registry Leif Panduro for help with the provision and interpretation of data. The working paper is part of Anne Hvenegaards ph.d.-thesis submitted to the Faculty of Social Science, University of Southern Denmark, 2010. The thesis is supervised by Dorte Gyrd-Hansen, Jacob Nielsen Arendt and Andrew Street. 


\section{References}

1.Ankjær-Jensen A., Rosling P., Bilde L.: Variable prospective financing in the Danish hospital sector and development of a Danish case-mix system. Health Care Management Science. 9, 259-268 (2006).

2.Carey K., Burgess J.: On measuring the hospital cost/quality trade-off. Health Economics. 8, 509520 (1999).

3.Classen D.C., Pestotnik S.L., Evans R.S., Lloyd J.F., Burke J.P.: Adverse drug events in hospitalized patients. Excess length of stay, extra costs, and attributable mortality. JAMA. 277, 301-306 (1997).

4.Clement J.P., Valdmanis V.G., Bazzoli G.J., Zhao M., Chukmaitov A.: Is more better? An analysis of hospital outcomes and efficiency with a DEA model of output congestion. Health Care Management Science. 11, 67-77 (2008).

5.Dimick J.B., Pronovost P.J., Cowan J.A., Lipsett P.A.: Complications and costs after high-risk surgery: where should we focus quality improvement initiatives? Journal of the American College of Surgeons. 196, 671-678 (2003).

6.Dismuke C.E., Sena V.: Is there a trade-off between quality and productivity? The case of diagnostic technologies in Portugal. Annals of Operational Research. 107, 101-116 (2001).

7.Fargher N., Morse D.: Quality costs: planning the trade-off between prevention and appraisal activities. Journal of Cost Management. 12, 14-23 (1998).

8.Fleming S.T.: The relationship between quality and cost. Inquiry. 28, 29-38 (1991).

9.Gertler P.J., Waldman D.M.: Quality-adjusted Cost Functions and Policy Evaluation in the Nursing Home Industry. The Journal of Political Economy. 100, 1232-1256 (1992).

10.Gravelle H.: Measuring income related inequality in health: standardisation and the partial concentration index. Health Economics. 12, 803-819 (2003).

11.Hall P.: On the bootstrap and likelihood-based confidence regions. Biometrika. 74, 481-493 (1987).

12.Harper J., Hauck K., Street A.: Analysis of costs and efficiency in general surgery specialties in the United Kingdom. HEPAC Health Economics in Prevention and Care. 2, 150-157 (2001).

13.Hauck K., Street A.: Performance assesssment in the context of multiple objectives: A multivariate multilevel analysis. Journal of Health Economics. 25, 1029-1048- (2006).

14.Hollingsworth B.: The measurement of efficiency and productivity of health care delivery. Health Economics. 17, 1107-1128 (2008).

15.Laine J., Finne-Soveri U.H., Bjorkgren M., Linna M., Noro A., Hakkinen U.: The association between quality of care and technical efficiency in long-term care. International Journal for Quality in Health Care. 17, 259-267 (2005). 
16.Lang T.A., Hodge M., Olson V., Romano P.S., Kravitz R.L.: Nurse-patient ratios: a systematic review on the effects of nurse staffing on patient, nurse employee, and hospital outcomes. The Journal of Nursing Administration. 34, 326-337 (2004).

17.Maniadakis N., Hollingsworth B., Thanassoulis E.: The impact of the internal market on hospital efficiency, productivity and service quality. Health Care Management Science. 2, 75-85 (1999).

18.McKay N.L., Deily M.E.: Cost inefficiency and hospital health outcomes. Health Economics. 17, 833-848 (2008).

19.Mitton C., Dionne F., Peacock S., Sheps S.: Quality and cost in healthcare: a relationship worth examining. Applied Health Economics and Health Policy. 5, 201-208 (2006).

20.Møller Pedersen K.: Sundhedspolitik : Beslutningsgrundlag, beslutningstagen og beslutninger i sundhedsvæsenet. Odense, Syddansk Universitetsforlag (2005).

21.Morey R.C., Fine D.J., Loree S.W., Retzlaff-Roberts D.L., Tsubakitani S.: The trade-off between hospital cost and quality of care. An exploratory empirical analysis. Medical Care. 30, 677-698 (1992).

22.Nayar P., Ozcan Y.A.: Data envelopment analysis comparison of hospital efficiency and quality. Journal of Medical Systems. 32, 193-199 (2008).

23.Olsen K.R., Street A.: The analysis of efficiency among a small number of organisations: How inferences can be improved by exploiting patient-level data. Health Economics. 17, 671-681 (2008).

24.Pinilla J., Murillo C., Carrasco G., Humet C.: Case-control analysis of the financial cost of medication errors in hospitalized patients. The European Journal of Health Economics. 7, 66-71 (2006).

25.Plowman R., Graves N., Griffin M.A., Roberts J.A., Swan A.V., Cookson B. et al.: The rate and cost of hospital-acquired infections occurring in patients admitted to selected specialties of a district general hospital in England and the national burden imposed 2. J Hosp.Infect. 47, 198-209 (2001).

26.Prior D.: Efficiency and total quality management in health care organizations: A dynamic frontier approach. Annals of Operational Research. 145, 281-299 (2006).

27.Prior D., Sola M.: Technical efficiency and economies of diversification in health care. Health Care Management Science. 3, 299-307 (2000).

28.Rampling A., Wiseman S., Davis L., Hyett A.P., Walbridge A.N., Payne G.C. et al.: Evidence that hospital hygiene is important in the control of methicillin-resistant Staphylococcus aureus. Journal of Hospital Infection. 49, 109-116 (2001).

29.Schmidt P., Sickles R.C.: Production Frontiers and Panel data. Journal of Business and Economic Studies. 2, 299-326 (1984).

30.Schneiderman A.M.: Optimum quality costs and zero defects: are they contradictory concepts? Quality Progress. Nov., 1-4 (1986). 
31.Schokkaert E., Van de Voorde C.: Risk selection and the specification of the conventional risk adjustment formula. Journal of Health Economics. 23, 1237-1259 (2004).

32.Solá D., Prior D.: Measuring productivity and quality changes using data envelopment analysis: An application to Catalan hospitals. Financial Accountability and Management. 17, 219-245 (2001).

33.The Danish Vascular Registry : Annual Report 2001. In. www.karbase.dk, The Danish Vascular Registry (2001).

34. Wagstaff A.: Estimating efficiency in the hospital sector: A comparison of three statistical cost frontier models. Applied Economics. 21, 659-672 (1989).

35.Weech-Maldonado R., Shea D., Mor V.: The relationship between quality of care and costs in nursing homes. American Journal of Medical Quality. 21, 40-48 (2006).

36. Wooldridge J.M.: Econometric Analysis of Cross Section and Panel data. Cambridge,Mass, MIT Press (2001). 
Studies in Health Economics present the results of health economics research at Institute for Public Health, Health Economics, University of Southern Denmark. Professor Terkel Christiansen is editor of the series. He is professor of health economics and head of the department of Health Economics University of Southern Denmark.

Further information Institute of Public Health Department of Health Economics University of Southern Denmark J.B. Winsløvsvej 9, 1 DK-5000 Odense C Denmark Telephone: +4565503081

Fax: +4565503880 email: hmj@sam.sdu.dk ISBN nr.:978-87-89021-71-3 